\title{
Clinical and biochemical effects of gamma-vinyl Gaba in tardive dyskinesia
}

\author{
J M GAIO, P POLLAK, M HOMMEL, J PERRET \\ From the Clinique Neurologique, CHU Grenoble, France
}

SUMMARY Clinical and biochemical effects of Gamma-vinyl-Gaba (GVG) have been evaluated in a blind video-controlled study in 10 psychiatric patients (mean age $71 \mathrm{yr}$ ) with tardive dyskinesia. CSF free and total Gaba and homocarnosine concentrations increased from three to five fold with GVG treatment. Despite the GVG-induced biological effects on Gaba metabolism, GVG did not consistently improve tardive dyskinesia. Psychomotor side-effects occurred in older patients, who $\mathcal{O}_{0}$ only tolerated GVG dosages of $2-4 \mathrm{~g} /$ day.

Tardive dyskinesia, a neurological disorder of abnormal hyperkinetic movement, is a frequent side effect of chronic administration of neuroleptic treatment. ${ }^{1}$ It occurs in predisposed patients, in whom it may become a persistent problem for which no entirely satisfactory treatment is known. ${ }^{2}$ The pathophysiology of tardive dyskinesia has not been definitively elucidated but the most widely accepted hypothesis is the development of dopamine receptor hypersensitivity of the striatum following prolonged exposure to neuroleptics. ${ }^{1-3}$ In chronically neuroleptic treated laboratory animals, the coadministration of Gabaergic agonists has been shown to prevent the occurrence of apomorphine-induced stereotypes ${ }^{4}$ and to inhibit neuronal dopaminergic activity. ${ }^{5}$ Therefore Gabaergic agonists might be effective agents to treat tardive dyskinesia in humans. Clinical trials using drugs with putative Gabaergic activity have produced mixed results. Thus, sodium valproate $^{6}$ and baclofen ${ }^{7}$ have been claimed to be slightly beneficial. Muscimol ${ }^{8}$ and $\gamma$-acetylenic Gaba $^{9}$ were also moderately effective but at the expense of unacceptable side effects. THIP was ineffective in tardive dyskinesia, with high doses being poorly tolerated. ${ }^{10}$

Address for reprint requests: Dr $\mathbf{J}$ M Gaio, Clinique Neurologique, CHRU Grenoble, BP 217 X, 38043 Grenoble Cedex, France.

Received 30 December 1986. Accepted 2 April 1987
Gamma-vinyl Gaba (GVG), an enzyme-activate irreversible inhibitor of Gaba-transaminase, producas large increases in brain Gaba concentrations of labo ratory animals. ${ }^{11}$ In addition, oral administration of GVG to man produces dose-related elevation of CSS Gaba content ${ }^{12}$ probably reflecting increased bra Gaba levels. ${ }^{13}$ In a pilot single blind study with taẹ dive dyskinesia patients, the administration of GVG $\overrightarrow{0}$ reduced the hyperkinesia scores of six of nine patients $\stackrel{\infty}{-}$ without producing major side effects. ${ }^{14}$ Similar results were subsequently observed in several single blind placebo controlled studies. ${ }^{15-18} \mathrm{We}$ also have carried out a single blind placebo controlled study with additional blind videotape rating of the effects of GVG in tardive dyskinesia patients. The clinical and biological effects of this treatment are reported.

\section{Patients and methods}

Ten elderly patients (55-85 years old, mean 71) hospitalised in a psychiatric institution were selected for the study. They were physically healthy and had exhibited stable tardive dyskinesia for at least 6 months prior to the study. They all gave informed consent. Relevant individual patient data are shown in the table. Five patients (Nos 2, 4, 5, 6, 9) entered the study with a concomitant neuroleptic treatment which had been maintained at the same dosage for at least the 윽 previous 3 months. The other patients had been off neuroleptic treatment for 1 to 3 years owing to their stable psychiatric condition. Two of the neuroleptic-treated patients (Nos 6,9) were also receiving anticholinergic drugs. N Neuroleptic and anticholinergic drugs dosage remained 
Table Individual patient data

\begin{tabular}{|c|c|c|c|c|c|c|c|c|c|}
\hline Patient & Sex & $\begin{array}{l}\text { Age } \\
(y r)\end{array}$ & $\begin{array}{l}\text { Psychiatric } \\
\text { diagnosis }\end{array}$ & $\begin{array}{l}\text { Duration of } \\
\text { psychiatric } \\
\text { illness }(y r)\end{array}$ & $\begin{array}{l}\text { Duration of } \\
T D(y r)\end{array}$ & $\begin{array}{l}\text { Duration of } \\
\text { previous } \\
\text { neuroleptic } \\
\text { treatment }(y r)\end{array}$ & $\begin{array}{l}\text { Concurrent } \\
\text { neuroleptic drug } \\
\text { treatment } \\
\text { dose } \mathrm{mg} / \mathrm{d}\end{array}$ & & $\begin{array}{l}\text { GVG } \\
\text { Maximum } \\
\text { dosage } \\
\text { g/d }\end{array}$ \\
\hline 1 & $\mathbf{M}$ & 58 & Residual schizophrenia & 22 & 2 & 22 & \multirow{3}{*}{ Propericiazine } & \multirow{3}{*}{15} & 6 \\
\hline 2 & $\mathrm{~F}$ & 59 & Cyclothymic disorder & 15 & 2 & 15 & & & 6 \\
\hline 3 & $\mathrm{~F}$ & 85 & Schizophrenia & 20 & 5 & 20 & & & 4 \\
\hline 4 & $\mathrm{~F}$ & 76 & Atypical depression & 6 & 3 & 6 & \multirow{3}{*}{$\begin{array}{l}\text { Tiapride } \\
\text { Tiapride } \\
\text { Thioridazine } \\
\text { Pipamperone } \\
\text { Chlorpromazine }\end{array}$} & \multirow{3}{*}{$\begin{array}{l}600 \\
100 \\
100 \\
120 \\
300\end{array}$} & 3 \\
\hline 5 & $\mathrm{~F}$ & 81 & Paranoia & 10 & 9 & 10 & & & 2 \\
\hline 6 & $\mathbf{M}$ & 55 & Paranoid schizophrenia & 35 & 1 & 9 & & & 6 \\
\hline 7 & M & 66 & \multirow{3}{*}{$\begin{array}{l}\text { Paranoia } \\
\text { Paranoid schizophrenia } \\
\text { Senile dementia } \\
\text { Paranoia } \\
\text { Senile dementia }\end{array}$} & 7 & 2 & 7 & & & 5 \\
\hline 8 & $F$ & 83 & & 20 & 7 & 20 & & & 3 \\
\hline 9 & $\mathrm{~F}$ & 74 & & 6 & 3 & 6 & Thioridazine & 150 & 2 \\
\hline \multirow{2}{*}{$\begin{array}{l}10 \\
\text { Mean } \\
\quad \pm S D\end{array}$} & $\mathrm{~F}$ & 72 & Cyclothymic disorder & 54 & 7 & 29 & & & 1 \\
\hline & \multicolumn{2}{|c|}{$70 \cdot 8 \pm 11 \cdot 9$} & & $19 \cdot 5 \pm 15 \cdot 2$ & $4 \cdot 1 \pm 2 \cdot 7$ & $16 \cdot 4 \pm 8.9$ & & & $3.8 \pm 1.8$ \\
\hline
\end{tabular}

unchanged throughout the study. The study began with a 2 week placebo period, followed by a 6 week period of GVG, and a final 2 week placebo period during which the patients received the same daily number of tablets as during the last week of GVG treatment. GVG or placebo was given twice daily. The starting dose of GVG was $1 \mathrm{~g} /$ day, this dose being increased by $1 \mathrm{~g} /$ day each week, to a maximum of $6 \mathrm{~g} /$ day. Should any dosage less than $6 \mathrm{~g} /$ day abolish all signs of tardive dyskinesia or be poorly tolerated, then that dose was maintained for the rest of the study.

\section{Clinical evaluations}

Symptoms of hyperkinesia and of Parkinsonism were recorded twice during the first week and then once weekly, with a videotape camera, at the same time of the day during a 10 minute standardised examination. ${ }^{19}$ At the end of the study all tapes were examined by the same rater who was blind as to the treatments. The rating scale for tardive dyskinesia included the examination of 10 body regions, each scored 0 to 4 according to the severity of the symptoms. ${ }^{19}$ The Parkinsonian symptoms were rated on 22 items also scored 0 to 4 for severity. ${ }^{19}$

\section{Biological evaluations}

Routine safety biological tests were performed during the initial placebo period and repeated on the last day of the active treatment period. Lumbar CSF was obtained from seven consenting patients at the end of the initial placebo period and the 6-weck GVG period. CSF was drawn at 8:00 am from fasting patients in the supine position. The 5th to 10 th millilitres of CSF were collected as one $\mathrm{ml}$ fractions into tubes kept in dry ice. Each sample was immediately frozen at $-70^{\circ} \mathrm{C}$ until analysis. Free and total Gaba, homocarnosine and GVG were assayed as previously described. ${ }^{12}$ Blood Gaba and GVG concentrations were also analysed on the last day of the initial placebo period and once weekly during the GVG treatment period.

Statistical analysis of the effects of GVG on tardive dyskinesia and Parkinsonism was made using Newman-Keuls test for individual scores and Student's $t$ test for global scores. Linear regression analysis was used for clinicobiological correlations.

\section{Results}

On the whole GVG had no significant effect on dyskinetic nor Parkinsonian symptoms at any dosage (fig 1). With GVG $2 \mathrm{~g}$ /day tardive dyskinesia scores slightly but not significantly improved. Individual data did not show any sustained improvement and a
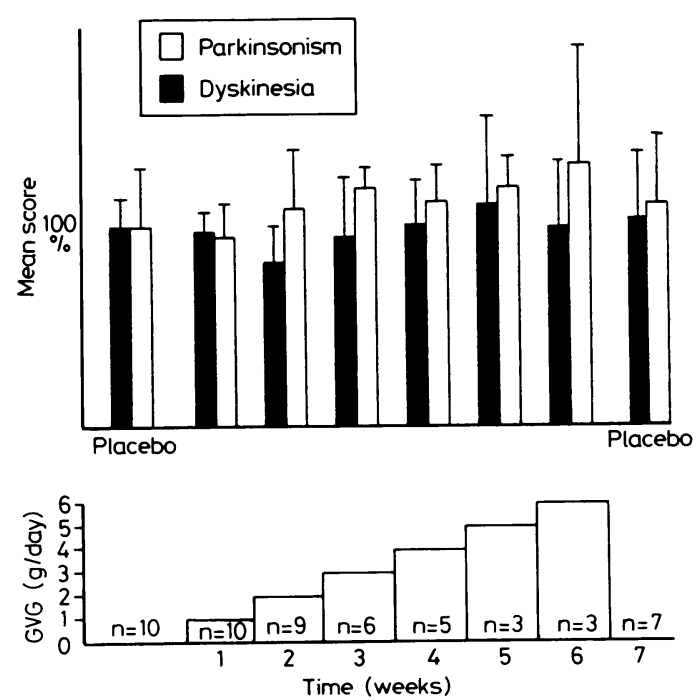

Fig 1 Mean tardive dyskinesia and Parkinsonian scores. Scores are expressed on percentage, $100 \%$ representing the initial placebo scores. The columns represent the average of the scores of all the patients taking the same dosage. $n$ is the number of patients for each dosage. 


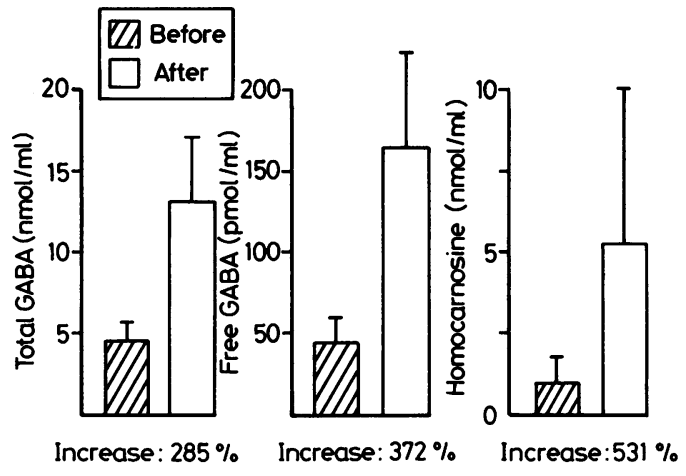

Fig 2 Total Gaba, free Gaba and homocarnosine CSF concentrations before and after oral GVG administration (mean dosage: $3.8 \mathrm{~g} /$ day) in seven dyskinetic patients.

slight Parkinsonian aggravating effect was observed in two patients (Nos 2, 4). Six patients completed the entire study. Of the four other patients, one (No 6) was withdrawn during the second placebo period

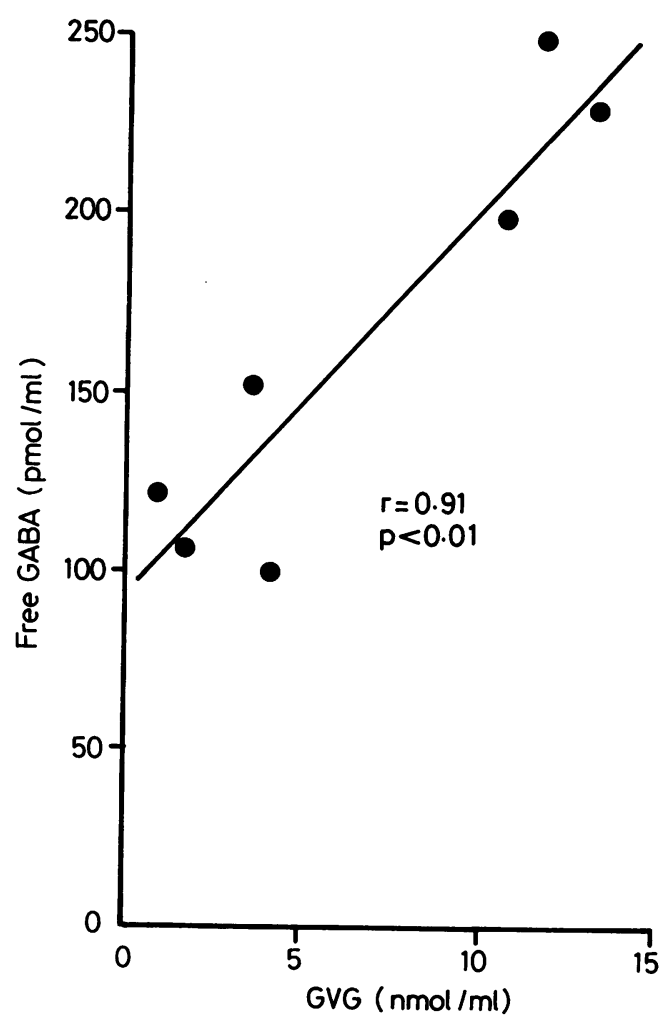

Fig 3 Correlation between CSF GVG concentrations and CSF free Gaba levels. because of reappearance of psychotic symptoms. Three patients stopped the study at the 6th week (No 7) 3rd week (No 9) and 2nd week (No 10) of the GVG period because of bad compliance. The maximum dosage of GVG ranged from $1 \mathrm{~g} /$ day to $6 \mathrm{~g} /$ day (mean $3.8 \mathrm{~g} /$ day \pm 1.8 ). Side effects occurred in four patients (Nos 3, 4, 8, 9) consisting of bradypsychia, confusion, drowsiness and shuffling gait; all of these four patients were more than 74 years old, and two of them were slightly demented before the onset of the study. Oral GVG dosage was significantly related to serum and CSF concentrations but not to serum Gaba levels (data not shown). In all of the seven studied patients CSF concentrations of Gaba (free and total) and homocarnosine increased with GVG treatment from three to five-fold (fig 2). The increase of CSF free Gaba was proportional to the CSF GVG levels (fig 3) but did not correlate with oral treatment dosage. The elevations of free Gaba serum concentrations and CSF free Gaba concentrations were not related $(p=$ $0 \cdot 18$ ). Standard laboratory data were not modified after GVG treatment.

\section{Discussion}

As no convenient long-term treatment is known foe tardive dyskinesia using drugs acting on dopaminer@ gic function, several studies have been performed with $\vec{B}$ Gaba agonists. ${ }^{6-10}$ They produced mixed resultso ranging from no improvement ${ }^{10}$ to mild improve ment $^{679}$ and in this last case ${ }^{9}$ the improvement was generally accompanied by an increase in Parkinson ism. GVG has been reported by several centres to reduce the hyperkinetic symptoms of patients with tardive dyskinesia. ${ }^{14-18}$ This beneficial effect was not confirmed in our placebo-controlled study. There is no obvious single explanation for this discrepancy, but when the patient population and the GVG regimen are compared across studies, several points can be mentioned. The lack of effect of GVG in our study cannot simply be due to problems of compliance. Not only was the administration of the medication carefully monitored, but the biological results also show that GVG was found in the patients' CSF and that CSF free Gaba concentrations increased proportionally to GVG CSF levels. The question of associated neuroleptic treatment was raised in a study ${ }^{9}$ where the positive effects of gamma-acetylenic Gaba correlated with the strength of concomitant neuroleptic treatment. In studies with GVG, however, improvement of tardive dyskinesia was observed independently from neuroleptic treatment. ${ }^{16}{ }^{18}$ In the present study half of the subjects were receiving neuroleptics, and their responses were not different from those patients not on neuroleptic treatment. The major difference between our study and those pre- 
viously reported is the high mean age of our patient population. Six of our 10 patients were over 70 years old, a much larger proportion than in the other reports. This may have several consequences. It has been suggested that tardive dyskinesia is less likely to be irreversible as age increases, ${ }^{20}$ thus making any treatment less effective in old people.

It is possible that, since we have used a rapidly escalating schedule of GVG dosing with only one clinical evaluation of each dose, we may have missed a "therapeutic window". In the study by Danion et $a l^{17}$ a beneficial effect of GVG was observed at $1 \mathrm{~g}$ /day after 2 weeks of administration. Tamminga et al $^{15}$ also observed $44 \%$ mean decrease in total dyskinetic symptoms at $3 \mathrm{~g} /$ day. If the beneficial effect of GVG occurs with an average dose of 1-3 g/day this improvement could have been missed in our study because five patients received at least 4 or more g/day of GVG.

Gaba is the most ubiquitous of cerebral neurotransmitters involved in both neurotransmission and intermediary metabolism. The widely accepted effect of Gaba as a neurotransmitter is an inhibitory one. But in animals, studies which alter the local Gabaergic neuronal activity show different and sometimes conflicting behavioural motor modifications dependant upon the neuronal structure involved and even the exact locus inside this structure. ${ }^{2122}$ Thus, one of the explanations of the lack of a clear clinical motor effect of GVG could be this various involvement of Gabaergic systems in the CNS.

The increase in Parkinsonism scores seen in two patients taking neuroleptics is in agreement with the results of other clinical studies. ${ }^{89}$ Such a hypokinetic effect is seen in rodents where Gaba agonists aggravate neuroleptic-induced catalepsy. ${ }^{23}$ Additionally, it appears from this and other reports ${ }^{14} 16$ that the tolerance to GVG decreases with age. The four younger patients of our study (less than 70 years old) tolerated GVG doses up to 4-6 g/day whereas the older patients tolerated only doses of $2-4 \mathrm{~g} /$ day. Furthermore, the four patients of our study who presented side effects all belonged to the older patient group. Similarly, the two patients of the Korsgaard's study who developed confusion were 70 and 78 years old; this side effect being not observed in the seven patients under $70 .^{16}$ Therefore we may have reached the limit of tolerance in most patients without disclosing any beneficial effects of the drug.

GVG produced a three to five-fold increase in CSF concentrations of frec Gaba, total Gaba and homocarnosinc. These CSF increases are better related to GVG CSF levels than GVG oral dosage, favouring a direct effect of GVG on CNS. The increase in CSF Gaba probably reflects a similar increase in human brain concentrations, as has been demonstrated in rat studies. ${ }^{13}$ Some Gabaergic drugs can induce such modifications in CSF Gaba concentrations. Valproic acid only produces a moderate increase of $77 \% .^{24}$ Isoniazid-induced elevation of CSF Gaba is obtained with unusually high oral doses. ${ }^{25}$ Biological results similar to ours are found in patients with Huntington's disease treated with $\gamma$-acetylenic $\mathrm{Gaba},{ }^{26}$ but this drug causes major side effects. Thus far, GVG appears to be the best tolerated drug capable of elevating brain Gaba concentrations. However, despite the obvious GVG-induced biological effects on the CNS Gaba system, GVG did not produce any clear benefit in an elderly group of psychiatric patients suffering from tardive dyskinesia.

We thank B Guerin for his technical assistance, and C Palao for the manuscript preparation.

Biochemical determination was carried out by the staff at Merrell Dow Research Institute, Strasbourg, France, who assume no responsibility for clinical results and discussion of this manuscript.

\section{References}

1 Tarsy D, Baldessarini RJ. The tardive dyskinesia syndrome. In: Klawans HL, ed. Clinical Neuropharmacology vol. 1. New York: Raven Press, 1976:29-61.

2 Simpson GM, Pi EH, Sramek JJ. Management of tardive dyskinesia: current update. Drugs 1982;23:381-93.

3 Baldessarini RJ. The pathophysiological basis of tardive dyskinesia. TINS 1979;2:133-6.

4 Lloyd KG, Worms $P$. Sustained gamma aminobutyric acid receptor stimulation and chronic neuroleptic effects. Adv Biochem Psychopharmacol 1980;24:253-8.

5 Biggio G, Casu M, Corda MG, Vernaleone F, Gessa GL. Effect of the muscimol a gaba-mimetic agent, on dopamine metabolism in the mouse brain. Life Sci 1977;21:525-32.

6 Linnoila M, Viukari M, Hietala D. Effect of Sodium valproate on tardive dyskinesia. Br J Psychiatry 1976;129:4-9.

7 Nair NPV, Yassa R, Ruiz-Navarro J, Schwartz G. Baclofen in the treatment of tardive dyskinesia. Am J Psychiatry 1978;135:1562-3.

8 Tamminga CA, Crayton JW, Chase TN. Improvement in tardive dyskinesia after muscimol therapy. Arch Gen Psychiatry 1979;36:595-8.

9 Casey DE, Gerlach J, Magelund G, Christensen TR. $\gamma$-acetylenic Gaba in tardive dyskinesia. Arch Gen Psychiatry 1980;37: 1376-9.

10 Korsgaard S, Casey DE, Gerlach J, Hetmar O, Kaldan B, Mikkelsen LE. The effect of THIP, a new GABA agonist, in tardive dyskinesia. Arch Gen Psychiatry 1982;39:1017-23.

11 Jung MJ, Lippert B, Metcalf BW, Böhlen P, Schechter PJ. $\gamma$-vinyl GABA (4 amino-hex-5-enoic acid) a new selective inhibitor of GABA-T: effects on brain GABA metabolism in mice. $J$ Neurochem 1977;29:797-802.

12 Grove J, Schechter PJ, Tell G, et al. Increased gammaaminobutyric acid (Gaba) homocarnosine and beta-alanine in cerebrospinal fluid of patients treated with gamma-vinyl-Gaba. Life Sci 1981;28:2431-9.

13 Böhlen P, Huot S, Palfreyman MG. The relationship between Gaba concentrations in brain and cerebrospinal fluid. Brain Res 1979;167:297-305.

14 Tell GP, Schechter PJ, Koch-Weser J, Cantiniaux P, Chabannes 
JP, Lambert PA. Effects of $\gamma$-vinyl Gaba. $N$ Engl $J$ Med 1981;305:581-2.

15 Tamminga CA, Thaker GK, Ferraro TN, Hare TA. Gaba agonist treatment improves tardive dyskinesia. Lancet 1983;ii: 97-8.

16 Korsgaard S, Casey DE, Gerlach D. Effect of gamma-vinyl GABA in tardive dyskinesia. Psychiatr Res 1983;8:261-9.

17 Danion DM, Singer L, Tell G, Schechter P. Gamma-vinyl GABA et dyskinesies tardives: une étude en simple insu contre placebo. Ann Med Psychol 1984;1:101-9.

18 Stahl SM, Thornton JE, Simpson ML, Berger PA, Napoliells MJ. Gamma-vinyl GABA treatment of tardive dyskinesia and other movement disorders. Biol Psychiatry 1985;20:888-93.

19 Pollak P, Gaio JM, Hommel M, Pellat J, Perret J. Effects of tiapride in tardive dyskinesia. Psychopharmacology 1985;85: 236-9.

20 Smith JM, Baldessarini RJ. Changes in prevalence, severity and recovery in tardive dyskinesia with age. Arch Gen Psychiatry 1980;37:1368-73.

21 Reavill C, Jenner P, Leigh N, Marsden CD. Turning behaviour induced by injection of muscimol or picrotoxin into the substantia nigra demonstrates dual Gaba components. Neurosci Lett 1979;12:323-8.

22 Starr MS, Kilpatrick IC. Nigral-derived muscimol circlingipsiversive contraversive or controversial. Nature 1981;290: 610.

23 Worms P. Lloyd KG. Influence of Gaba agonists and antogonists on neuroleptic-induced catalepsy in rats. Life Sci 1978;23: 475-8.

24 Löscher W. Gaba in plasma and cerebrospinal fluid of different species. Effects of $\gamma$-acetylenic Gaba, $\gamma$-vinyl Gaba and sodium valproate. J Neurochem 1979;32:1587-91.

25 Manyam BV, Katz L, Hare TA, Kaniefski K, Tremblay RD. Isoniazid-induced elevation of CSF Gaba levels and effect on chorea in Huntington's disease. Ann Neurol 1981;10:35-7.

26 Tell G, Schechter PJ, Koch-Weser J, et al. Treatment of Huntington's disease with $\gamma$-acetylenic Gaba an irreversible inhibitor of Gaba-transaminase: increased CSF Gaba and homocarnosine without clinical amelioration. Neurology 1981;31:207-11. 